\title{
Prognostic Impact of the Metabolic Syndrome and Its Components in Acute Type A Aortic Dissection After Surgery: A 3-Year Follow-Up
}

\author{
Peng Liu \\ The First Hospital of Hebei Medical University \\ Feng Zhang \\ The First Hospital of Hebei Medical University \\ Zibin Wang \\ The First Hospital of Hebei Medical University \\ Miao Zhang \\ The First Hospital of Hebei Medical University \\ Xupeng Niu \\ The First Hospital of Hebei Medical University \\ Yaru Han ( $\sim$ hyr1863388889@163.com ) \\ The First Hospital of Hebei Medical University
}

\section{Research Article}

Keywords: Acute type A aortic dissection, metabolic syndrome, poor outcome, components, score system

Posted Date: December 13th, 2021

DOI: https://doi.org/10.21203/rs.3.rs-1131517/v1

License: (c) (i) This work is licensed under a Creative Commons Attribution 4.0 International License. Read Full License 


\section{Abstract \\ Background}

The aim of this study is to explore whether or to what extent the metabolic syndrome (METs) and its components was associated with poor outcome in acute type A aortic dissection patients (ATAAD) after surgery.

\section{Methods}

This study involved 353 ATAAD patients undergo surgery. Data on demographic and clinical characteristics were collected. Subgroup analysis, mixed models regression analysis, score systems and receiver-operating characteristic curves (ROC) analysis were done.

\section{Results}

Overall, 353 inpatients were assigned to the poor outcome group $(n=69)$ and control group $(n=284)$ with or without METs. Compared to control group, the incidence of METs was higher in poor outcome group. Poor outcome were present in $0 \%, 4.4 \%, 12.3 \%, 47.6 \%, 71.4 \%$ and $100 \%$ of the six groups, who met the diagnostic criteria of MetS $0,1,2,3,4$ and 5 times. For multivariable logistic regression, quartiles of BMI remained the risk factors of poor outcome after adjustment other risk factors. After adjustment for potential confounding factors, METs was an independent risk factors in several models. Assigning a score of one for each components, the AUC were 0.877 (95\% Cl: $0.823-0.923)$ in all patients, 0.864 ( $95 \% \mathrm{Cl}: 0.7945-0.935)$ in $\mathrm{METs}$ and 0.700 (95\% Cl: $0.567-0.833)$ in non-METs by Receiver-operating characteristic.

\section{Conclusions}

METs, especially for BMI, confers greater risk for poor outcome in ATAAD after surgery during 3-year follow up.

\section{Introduction}

Acute type A aortic dissection (ATAAD) is a life-threatening cardiovascular disease with high mortality, which characterized by a tear in the ascending aortic intima allowing blood to travel along the length of the aorta[1]. Historically, medical intervention was common therapy to limit dissection, alleviating pain and control hypertension. With significant improvements in surgical methods and techniques, the early mortality of ATAAD was decrease[2]. Due to older, comatose state, long operating times, the outcome was still high for ATAAD. Previous study found body mass index was an independent prognosis risk factor of aortic dissection patients, which indicated Obesity may play a critical role in the process of disease[3]. Besidies, dyslipidemia, hypertension and diabetes also influence the prognosis in aortic dissection patients[4-6].

Metabolic syndrome (METs) is often ignored in clinic practice and comprises five components, BMI, blood pressure, fasting plasma glucose, high-density lipoprotein and triglycerides[7]. As a complex disorder, METs was an independent risk factor of cardiovascular diseases and influence outcome of patients. The relationship between METs and aortic dissection was not describe[8]. In present study, we investigated the association of the METs and its components with the outcome of ATAAD after surgery and deduced the usefulness of the METs for the diagnosis and risk assessment of ATAAD in clinical practice,which also provide a new sight for the incidence and outcome of ATAAD.

\section{Methods}

\section{Study cohort}

This is an retrospective study. A total of 353 consecutive ATAAD patients who received surgery in the Department of General Surgery at the First Hospital of Hebei Medical University were enrolled in this study from January 2013 to January 2018. The inclusion criteria were as follows: 1) diagnosed with ATAAD confirmed by CT angiography of the aorta and 2) underwent surgical treatment. The major exclusion criteria included the following: 1) other causes of aortic dissection such as Marfan syndrome; 2) patients who did not undergo surgery; 3) with other system serious diseases; 4) other causes of aortic dissection such as Marfan syndrome. The study was approved by the Institutional Review Board of the First Hospital of Hebei Medical University. All subjects provided written informed consent. The detailed recruitment process is shown in Figure 1.

\section{Baseline demographic and clinical characteristics}

Data regarding sex, age, body mass index (BMI), blood pressure, heart rate (HR), systolic blood pressure (SBP), diastolic blood pressure (DBP), ventricular ejection fraction (LVEF), history of hypertension (HT), type 2 diabetes mellitus (T2DM), coronary artery disease (CAD) and thoracic surgery were collected. Preoperative laboratory tests were performed within $24 \mathrm{~h}$ before surgery, including tests for fasting blood glucose (FBG), triglycerides (TG), highdensity lipoprotein cholesterol (HDL-C), white blood cells (WBCs), platelets (PLTs), creatinine (Cr), uric acid (UA), troponin I, and red blood cells (RBCs). Surgery variables included length of surgey, cardiopulmonary bypass time, cross-clamp time, circulatory arrest, minimum temperature, ICU stay time, hospital stay time.

\section{Metabolic syndrome}


According to the criteria of the American National Cholesterol Education Program[9], MetS was defined as the presence of three or more of the following criteria: body mass index (BMI) $>30 \mathrm{~kg} / \mathrm{m}^{2}$, high-density lipoprotein (HDL) $<50 \mathrm{mg} / \mathrm{dL}$ among women and $<40 \mathrm{mg} / \mathrm{dL}$ among men, fasting plasma triglycerides (TG) $\geq 150 \mathrm{mg} / \mathrm{dL}$, systolic blood pressure (SBP) $\geq 130 \mathrm{mmHg}$, diastolic blood pressure (DBP) $\geq 85 \mathrm{mmHg}$, fasting plasma glucose (FPG) $\geq 100$ $\mathrm{mg} / \mathrm{dL}$ or previously diagnosed type 2 diabetes mellitus (T2DM).

\section{Follow-Up}

Poor outcome were included all-cause death, hospitalization for recurrence aortic dissection or aortic surgery and systemic-related diseases during 3 years follow-up. Systemic complications included stroke, renal failure, hepatic failure, heart failure, et al. The main methods of follow-up included outpatient review, telephone and visits by two doctors.

\section{Statistical methods}

Statistical computations were performed using SPSS v25.1 (IBM Inc., Armonk, NY, USA). Measurement data are reported as the mean \pm standard deviation for normally distributed data or as the median and quartiles $(\mathrm{Q} 1, \mathrm{Q})$ for nonnormally distributed data. Grade data are expressed as frequencies and percentages and were compared using the chi-square test. Multivariable Cox regression analyses were performed to detect the relationship between outcome and METs. In the multivariate analysis, hazard ratios (HRs) and 95\% confidence intervals (Cls) for Poor outcome were calculated using a coX regression model after adjusting for potential confounding variables. To verify the robustness of our results, subgroup analyses were performed to explore the association between the number of MetS components and adverse event. Survival curves were performed by using the Kaplan-Meier method.These predictors of metabolic syndrome components were assigned points based on their regression coefficient, and a scoring system was produced. Receiver operating characteristic (ROC) curves were constructed, and the areas under the curves (AUCs) were calculated to assess the discriminatory power of the scoring system for MetS. A two-sided $p$ value $<0.05$ was considered statistically significant.

\section{Results}

\section{Baseline characteristics}

353 patients were enrolled the study and 69 patients occur the poor outcome. Compared to control group, the age, BMI and FBG was higher in poor outcome group(all $P<0.001)$. For Mets, there were 49 patients $(71.0 \%)$ in poor outcome and 46 patients $(16.2 \%)$ in control group, respectively. Compared to control group, the incidence of HT was significantly higher in poor outcome for all patients (all $P<0.001$ ). Besides, compare to the control group, the age and BMI was higher in poor outcome for both Mets and non-Mets subgroup (all $P<0.001$ ). For Surgical procedure, there were no significant difference between overall and subgroup (all $P \otimes 0.05$ )(table 1$)$.

\section{The METs number and clinical characteristics}

Patients were divided into six groups: 14 (4.0\%), 137(38.8\%), 114(32.3\%), $63(17.8 \%), 21(5.9 \%)$ and 4(1.2\%) who met the diagnostic criteria of MetS 0, 1, 2, 3, 4 and 5 times, respectively. Poor outcome was present in $0 \%, 4.4 \%, 12.3 \%, 47.6 \%, 71.4 \%$ and $100.0 \%$ of the six groups, which indicated the statistically differences $(P<0.05$, table 2 Figure 2). There were significant difference in BMI, HT, T2DM, SBP, DBP, FBG, TG,HDL-c among six group (all $P \otimes 0.05)$. For comparison among groups囚the difference were the most in BMI.

\section{METs components and In-hospital complications}

After adjustment for some risk factors, such as male, age, smoker, aortic valve disease, peripheral vascular disease, hospital stay, the quartiles of BMI (adjusted HR $=1.422,95 \% \mathrm{Cl} 1.205-1.678, P<0.05)$, HDL-C (adjusted HR =0.723, 95\% Cl 0.569-0.981, $P<0.05$ ) and FBG (adjusted HR =1.402, 95\% Cl 1.110$1.7711, P<0.05)$ remained independent factors of poor outcomes. HT was also independent risk factors of the incidence of adverse events. Compared with the first BMI quartile, the HRs were 2.727 (95\% Cl 1.617-4.597) and 3.306 (95\% Cl 2.135-5.492) for the third and fourth BMI quartiles, respectively, after adjusting for potential risk factors (Table 3 ).

\section{METs and Poor outcome}

Table 4 show the results of multivariate cox regression that the association between the poor outcome and MetS. There were five models after adjusted for Age,male,heart rate,Aortic valve disease,stroke,LVEF,Length of surgery,Cardiopulmonary bypass time,Cross-clamp time,Circulatory arrest,Isolated supracoronary ascending aorta replacement,total aortic arch replacement,total aortic arch replacement,partial aortic arch replacemen,others,smoker,WBC,PLT,ICU time, hospital stay time,CR,eGFR,UA. The HRs were 7.537, 7.369, 8.036, 8.137,9.905 for MetS in model 1, 2, 3, 4,5 ( all $P$ $<0.05$ ) (Table 4).

\section{Score system of METs and ROC}

Based on the Regression Coefficeint, point was assigned to METs components and subsequently summed to obtain a total difficulty score after adjusted for covariates. Elevated BMI was for 7, Elevated BP was for 3, Elevated FBG was for 3, Reduced HDL was for 2 and Elevated TG was for 1 (Table 5). The ROC curves were performed for score system. The AUC were 0.877 (95\%Cl: $0.823-0.932)$ in all patients, 0.864 (95\%Cl: 07945-0.935) in METs and 0.700(95\%Cl: 0.567-0.833) in non-METs. (Table 6, Figure 3).

\section{Discussion}


When the dissection involves the ascending aorta, the patients were defined as type A aortic dissection. With the improvement of anesthetic techniques, extracorporeal perfusion, types of prosthetic grafts and surgical techniques, the outcome was improved markedly. Due to the pathophysiology of aortic dissection, the Incidence of adverse events were still high[10].

One of our main findings was that METs values could significantly predict the incidence of poor outcome in ATAAD patients after surgery during 3 years follow-up by multivariable and subgroup analyses. After adjusting for confounding factors, METs was also an independent risk factor for adverse events. METs had five components, BMI, blood pressure, fasting plasma glucose, high-density lipoprotein and triglycerides[11].As a Complex and common disease, it ties together insulin resistance, visceral adiposity, dyslipidemia and hypertension, which were risk factors of cardiovascular diseases[12]. Previous studies had found that it components were associated with the outcome of aortic dissection.

Obesity was a risk factor of cardiovascular disease, which also exhibited effects on multiple systems, such as the respiratory and ureaplasmas systems[13]. Some underling changes were occurred in the heart for patients with high BMI level. Glucose metabolism to expanded fatty acid oxidation, insulin resistance, imbalance of hormones and inflammatory cytokines could contribute to the incidence of adverse events[14]. Besides, previous studies had found that BMI was an independent predictor of acute kidney injury in ATAAD after surgery and preoperative hypoxemia in ATAAD before surgery[15]. A study enrolled 777 ATAAD patients divided into three groups according to BMI. After analysis, BMI was an independently risk factors of in-hospital major adverse outcomes in patients after surgery[16]. Lio $A$ et al were found that ATAAD patients with $B M I \geq 30 \mathrm{~kg} / \mathrm{m}^{2}$ had higher operative mortality rates and an increased risk of low cardiac output syndrome, pulmonary complications and other postoperative morbidities after surgery[17]..In our study, BMI was the strongest predictor of the poor outcome during 3-year follow up by METs components analysis. For establish score system and ROC analysis, it was showed a better predictive power.

For blood blood glucose, there were controversial in the effect of ATAAD prognosis. In a clinical observational study, T2DM reduced the clinical complications and mortality in Stanford type B aortic dissection after thoracic endovascular aortic repair during 3-year follow up[18]. While, Lin YJ et al were found that glucose variability was associated with the incidence of postoperative delirium in acute aortic dissection patients[19]. For T2DM, there was not significant difference between two groups in our study. As a METS components, elevated blood glucose or T2DM was an independent factor of ATAAD prognosis after surgery. The specific mechanism was unclear. We speculated that the effect of insulin resistance were expanded by the synergism of other METs components, which triggered the common signal. Besides, The long-term outcome of ATAAT after surgery involved multiorgan and multisystem. Blood glucose or T2DM played an important role in other systems. In order to elucidate the underlying mechanism, the basic research and the influence of hemoglobin should perform in the future.

Hypertension was the common cause of aortic dissection that $72.1 \%$ of aortic dissection patients had history of hypertension. The high blood pressure aggravated hematoma expansion and expanded of false lumen. Therefore, the control of blood pressure was the main treatment of ATAAD and alleviated the chest pain[20].. It was also influenced the Renin-Angiotensin-Aldosterone System, sympathetic sensory system incitement and cytokines level, which related to the adverse events[21]. In Bossone E et al study, there was a J-curve association betwwen SBP and in-hospital mortality in acute aortic dissection[22]. In our study, blood pressure was an important factor to predict the adverse outcome.

TG were transported from the liver to peripheral tissues to meet energy needs. It had more direct effects on inflammatory responses.Besides, TG also involved the process of oxidative stress and aortic stiffness[23]. As a protect particles, HDL played pivotal role in reverse cholesterol transport, which also exert a protective influence on inflammation, oxidation, angiogenesis and glucose homeostasis[24]. For aortic dissection, increased TG and decreased HDL indicated the poor outcome. A study found that the in-hospital mortality was increased for type B acute aortic dissection patients When TG level was increased and HDL level was decreased. The TG/HDL ratio was an risk factor of in-hospital mortality[4]. In our study, reduced HDL was independent risks of poor outcome after adjusted for potential confounding variables. While, the function of TG was not robust.

When patient met multiple criteria and diagnosis METs, The risk were higher than met isolated one. Insulin resistance, inflammation and neurohormonal activation exert the synergistic effect. METs was an independent risk factors of outcome, which might also a risk factor of aortic dissection. There were several METs diagnostic criteria, such as National Cholesterol Education Program criteria (NCEP), International Diabetes Federation (IDF), and The American Heart Association/National Heart, Lung, and Blood Institute (AHA/NHLBI). Research found that NCEP MetS definition may be more suitable for Chinese population, So we So choice the NCEP criteria in our study. Recent study demonstrated that compared to AHA/NHLBI and IDF criterion, the prevalence of cardiovascular disease was more evident when MetS was defined according to the NCEP criterion (OR:1.40)[25].

There were some limitations in our study. First, this was a single-centre and not large number of enrolled patients, which may have introduced selection bias. Second, the underlying mechanistic link between MetS and adverse events is not clear that potential risks may affect the incidence of poor outcome. Further large and randomized controlled trial need to be done to confirm our results. Lastly, due to the inclusion of ATAAD patients undergoing surgery only, our conclusions might not be applicable to aortic dissection patients with conservative treatment.

\section{Conclusions}

For ATAAD patients after surgery, the occurrence of poor outcome seems tightly linked to METs during 3-year follow up, especially in BMI. After adjusted potential risks and established score system, METs was an independent risk factor for poor outcome during 3-year follow up.

\section{Declarations}

\section{Ethics approval and consent to participate}

The study protocol was approved by the Institutional Review Board of The First Hospital of Hebei Medical University, Shijiazhuang Hebei, China.

Page $4 / 11$ 


\section{Consent for publication}

Yes

\section{Availability of data and materials}

Data available on request from the authors

\section{Competing interests}

The authors declare that they have no competing interests

\section{Funding}

The Medical Science Research Project of the Key Research and development program of Hebei Province (No.20377732D)

\section{Authors' contributions}

Peng Liu: design of the work and have drafted the work;

Feng Zhang: the acquisition, analysis;

Zibin Wang: design of the work;

Miao Zhang: interpretation of data;

Xupeng Niu: interpretation of data;

Yaru Han: substantively revised it.

\section{Acknowledgements}

None

\section{References}

1. Ke C,Wu H,Xi M,Shi W,Huang Q,Lu G.Outcome after surgery for acute type A aortic dissection with or without primary tear resection.BMC Cardiovasc Disord. 2021;21:392.

2. Lin CY, Tung TH,Wu MY,Tseng CN,Tsai FC.Surgical outcomes of DeBakey type I and type II acute aortic dissection: a propensity score-matched analysis in 599 patients.J Cardiothorac Surg.2021;16:208.

3. Liu Y, Zhang B, Liang S,et al.Impact of body mass index on early and mid-term outcomes after surgery for acute Stanford type A aortic dissection.J Cardiothorac Surg.2021;16:179.

4. Zhou Y, Yang G, He H, Pan X, Peng W, Chai X.Triglyceride/High-Density Lipoprotein Cholesterol Ratio Is Associated with In-Hospital Mortality in Acute Type B Aortic Dissection.Biomed Res Int. 2020;2020:5419846.

5. Song C, Yu G, Feng X,et al.Impact of high blood pressure variability on the occurrence of acute type B aortic dissection.Vascular;2020;28:413-420.

6. Li S, Zhang L,Zhu G,Feng R,Zhou J,Jing Z.Diabetes Mellitus Lowers the Risk of Aortic Dissection: a Systematic Review and Meta-Analysis.Ann Vasc Surg.2021;74:209-219.

7. McCracken E, Monaghan M, Sreenivasan S.Pathophysiology of the metabolic syndrome.Clin Dermatol.2018;36:14-20.

8. Włodarski A, Strycharz J, Wróblewski A, Kasznicki J, Drzewoski J, Śliwińska A.The Role of microRNAs in Metabolic Syndrome-Related Oxidative Stress.Int J Mol Sci.2020;21:6902.

9. Ebrahimi H, Emamian MH, Khosravi A, Hashemi H, Fotouhi A.Comparison of the accuracy of three diagnostic criteria and estimating the prevalence of metabolic syndrome: A latent class analysis.J Res Med Sci.2019;24:108.

10. Zhu Y, Lingala B, Baiocchi M,et al.Type A Aortic Dissection-Experience Over 5 Decades: JACC Historical Breakthroughs in Perspective.J Am Coll Cardiol.2020;76:1703-1713.

11. Rochlani Y, Pothineni NV, Kovelamudi S, Mehta JL.Metabolic syndrome: pathophysiology, management, and modulation by natural compounds. Ther Adv Cardiovasc Dis.2017;11:215-225.

12. Said S, Mukherjee D, Whayne TF.Interrelationships with Metabolic Syndrome, Obesity and Cardiovascular Risk.Curr Vasc Pharmacol.2016;14:415-425.

13. Nikolopoulou A, Kadoglou NP.Obesity and metabolic syndrome as related to cardiovascular disease.Expert Rev Cardiovasc Ther.2012;10:933-9.

14. Yang Q, Ma Q, Xu J,et al.Endothelial AMPKa1/PRKAA1 exacerbates inflammation in HFD-fed mice.Br J Pharmacol.2021;doi: 10.1111/bph.15742. Online ahead of print.

15. Liu T, Fu Y, Liu J,et al.Body mass index is an independent predictor of acute kidney injury after urgent aortic arch surgery for acute DeBakey Type I aortic dissection.J Cardiothorac Surg.2021;16:145. 
16. Lin L, Lin Y, Chen Q,et al.Association of body mass index with in-hospital major adverse outcomes in acute type A aortic dissection patients in Fujian Province, China: a retrospective study. Cardiothorac Surg. 2021;16:47.

17. Lio A, Bovio E, Nicolò F,et al.Influence of Body Mass Index on Outcomes of Patients Undergoing Surgery for Acute Aortic Dissection: A Propensity-Matched Analysis. Tex Heart Inst J.2019;46:7-13.

18. Liu H, Shi L, Zeng T,et al.Type 2 diabetes mellitus reduces clinical complications and mortality in Stanford type B aortic dissection after thoracic endovascular aortic repair: A 3-year follow-up study.Life Sci.2019;230:104-110.

19. Lin YJ, Lin LY, Peng YC,et al.Association between glucose variability and postoperative delirium in acute aortic dissection patients: an observational study.J Cardiothorac Surg.2021;16:82.

20. Zhou JC, Zhang N, Zhang ZH,et al.Intensive blood pressure control in patients with acute type B aortic dissection (RAID): study protocol for randomized controlled trial.J Thorac Dis.2017;9:1369-1374.

21. Lu N, Ma X, Xu T,et al.Optimal blood pressure control for patients after thoracic endovascular aortic repair of type B aortic dissection.BMC Cardiovasc Disord.2019;19:124.

22. Bossone E, Gorla R, LaBounty TM,et al.Presenting Systolic Blood Pressure and Outcomes in Patients With Acute Aortic Dissection.J Am Coll Cardiol.2018;71:1432-1440.

23. Generoso G, Janovsky CCPS, Bittencourt MS.Triglycerides and triglyceride-rich lipoproteins in the development and progression of atherosclerosis.Curr Opin Endocrinol Diabetes Obes. 2019;26:109-116.

24. ornmueller K, Vidakovic I, Prassl R.Artificial High Density Lipoprotein Nanoparticles in Cardiovascular Research.Molecules.2019;24:2829.

25. Li W, Song F, Wang X,et al.Relationship between metabolic syndrome and its components and cardiovascular disease in middle-aged and elderly Chinese population: a national cross-sectional survey.BMJ Open.2019;9:e027545.

\section{Tables}

Table 1 Clinical characteristics in METs and No METs patients with poor outcome. 


\begin{tabular}{|c|c|c|c|c|c|c|c|}
\hline \multirow[t]{3}{*}{ Variables } & \multicolumn{3}{|l|}{ Overall } & \multicolumn{3}{|l|}{ MetS } & \multirow{2}{*}{$\begin{array}{l}\text { non-MetS } \\
\text { Poor Outcome }\end{array}$} \\
\hline & Poor Outcome & Control & $P$ & Poor Outcome & Control & $P$ & \\
\hline & $n=69$ & $\mathrm{n}=\mathbf{2 8 4}$ & & $n=49$ & $n=46$ & & $\mathrm{n}=\mathbf{2 0}$ \\
\hline Male,n(\%) & $50(72.5)$ & $214(75.4)$ & 0.620 & $33(67.3)$ & $32(69.6)$ & 0.816 & $17(85.0)$ \\
\hline Age,years & $56.4 \pm 5.1$ & $51.7 \pm 4.7$ & $<0.001$ & $55.4 \pm 4.9$ & $50.8 \pm 4.6$ & $<0.001$ & $58.9 \pm 4.9$ \\
\hline $\mathrm{BMI}, \mathrm{Kg} / \mathrm{m} 2$ & $29.2 \pm 3.1$ & $24.6 \pm 2.3$ & $<0.001$ & $29.7 \pm 3.0$ & $24.9 \pm 2.4$ & $<0.001$ & $27.9 \pm 3.0$ \\
\hline $\mathrm{HT}, \mathrm{n}(\%)$ & $52(75.4)$ & $150(52.8)$ & 0.001 & $39(79.6)$ & $26(56.5)$ & 0.016 & 13(65.0) \\
\hline T2DM,n(\%) & $15(21.7)$ & $47(16.5)$ & 0.310 & 15(30.6) & $16(34.8)$ & 0.665 & $0(0)$ \\
\hline $\mathrm{CAD}, \mathrm{n}(\%)$ & $8(11.6)$ & $36(12.7)$ & 0.807 & $6(12.2)$ & $15(32.6)$ & 0.017 & $2(10.0)$ \\
\hline $\begin{array}{l}\text { Aortic valve } \\
\text { disease,n(\%) }\end{array}$ & $6(8.7)$ & $18(6.3)$ & 0.485 & $5(10.2)$ & $4(8.7)$ & 0.802 & $1(14.0)$ \\
\hline $\begin{array}{l}\text { Metabolic } \\
\text { syndrome,n(\%) }\end{array}$ & $49(71.0)$ & $46(16.2)$ & $<0.001$ & - & - & - & - \\
\hline smoker,n(\%) & $26(37.7)$ & $72(25.4)$ & 0.040 & $20(40.8)$ & $9(19.6)$ & 0.025 & $6(30.0)$ \\
\hline Stroke,n(\%) & $5(7.2)$ & $26(9.2)$ & 0.615 & $4(8.2)$ & $6(13.0)$ & 0.439 & $1(5.0)$ \\
\hline $\begin{array}{l}\text { Peripheral vascular } \\
\text { disease, } \mathrm{n}(\%)\end{array}$ & $3(4.3)$ & $8(2.8)$ & 0.512 & $2(4.1)$ & $3(6.5)$ & 0.595 & $1(5.0)$ \\
\hline $\mathrm{SBP}, \mathrm{mmHg}$ & $143.2 \pm 12.0$ & $140.8 \pm 13.0$ & 0.160 & $143.6 \pm 12.9$ & $142.8 \pm 10.8$ & 0.755 & $142.2 \pm 9.7$ \\
\hline $\mathrm{DBP}, \mathrm{mmHg}$ & $81.1 \pm 7.1$ & $78.6 \pm 6.6$ & 0.001 & $81.2 \pm 7.6$ & $79.4 \pm 5.6$ & 0.195 & $82.6 \pm 5.6$ \\
\hline $\mathrm{HR}, \mathrm{bpm}$ & $70.6 \pm 11.3$ & $71.0 \pm 10.7$ & 0.757 & $69.8 \pm 12.0$ & $71.2 \pm 7.4$ & 0.513 & $72.4 \pm 9.5$ \\
\hline LVEF,\% & $56.1 \pm 5.8$ & $57.5 \pm 6.7$ & 0.115 & $55.0 \pm 5.9$ & $59.5 \pm 7.4$ & 0.002 & $58.7 \pm 4.7$ \\
\hline $\mathrm{FBG}, \mathrm{mmol} / \mathrm{L}$ & $6.4 \pm 1.7$ & $5.3 \pm 1.0$ & $<0.001$ & $6.8 \pm 1.7$ & $5.6 \pm 1.1$ & $<0.001$ & $5.3 \pm 1.1$ \\
\hline $\mathrm{TG}, \mathrm{mmol} / \mathrm{L}$ & $1.5(1.1,1.8)$ & $1.3(1.0,1.7)$ & 0.064 & $1.7(1.2,1.9)$ & $2.2(1.8,3.0)$ & $<0.001$ & $1.3(1.0,1.6)$ \\
\hline $\mathrm{HDL}-\mathrm{C}, \mathrm{mmol} / \mathrm{L}$ & $1.2(0.9,1.4)$ & $1.7(1.2,2.2)$ & $<0.001$ & $1.0(0.9,1.3)$ & $1.0(0.9,1.7)$ & 0.729 & $1.3(1.2,1.8)$ \\
\hline WBC,1012/L & $10.0 \pm 1.5$ & $10.0 \pm 1.5$ & 0.801 & $10.0 \pm 1.7$ & $10.4 \pm 1.4$ & 0.232 & $9.9 \pm 1.0$ \\
\hline PLT,109/L & $211.8 \pm 61.1$ & $222.2 \pm 57.2$ & 0.180 & $201.9 \pm 57.2$ & $212.1 \pm 51.5$ & 0.907 & $235.8 \pm 65.0$ \\
\hline $\mathrm{Cr}, \mu \mathrm{mol} / \mathrm{L}$ & $75.6 \pm 18.4$ & $76.3 \pm 19.1$ & 0.786 & $76.1 \pm 18.9$ & $82.5 \pm 28.7$ & 0.212 & $74.3 \pm 17.7$ \\
\hline $\mathrm{UA}, \mu \mathrm{mol} / \mathrm{L}$ & $338.2(271.0,435.3)$ & $346.7(302.1,407.0)$ & 0.578 & $335.8(273.8,437.6)$ & $369.3(311.8,418.2)$ & 0.403 & $339.6(255.3,430.9)$ \\
\hline $\begin{array}{l}\text { eGFR, } \mathrm{mL} /(\min \cdot 1.73 \\
\mathrm{m} 2)\end{array}$ & $90.8 \pm 15.8$ & $91.8 \pm 15.6$ & 0.643 & $89.9 \pm 17.1$ & $88.1 \pm 18.7$ & 0.643 & $93.3 \pm 12.0$ \\
\hline \multicolumn{8}{|l|}{ Surgical procedure } \\
\hline $\begin{array}{l}\text { Length of surgery, } \\
\text { min }\end{array}$ & $276.6 \pm 25.3$ & $275.8 \pm 23.7$ & 0.803 & $278.1 \pm 26.9$ & $278.4 \pm 21.1$ & 0.937 & $273.2 \pm 21.2$ \\
\hline $\begin{array}{l}\text { Cardiopulmonary } \\
\text { bypass time, min }\end{array}$ & $169.3 \pm 22.7$ & $168.7 \pm 23.8$ & 0.847 & $166.3 \pm 23.4$ & $168.6 \pm 18.9$ & 0.604 & $176.5 \pm 19.4$ \\
\hline $\begin{array}{l}\text { Cross-clamp time, } \\
\text { min }\end{array}$ & $89.1 \pm 14.6$ & $89.0 \pm 13.0$ & 0.953 & $89.1 \pm 15.1$ & $87.7 \pm 13.7$ & 0.652 & $89.1 \pm 13.6$ \\
\hline $\begin{array}{l}\text { Circulatory arrest, } \\
\text { min }\end{array}$ & $43.2 \pm 7.6$ & $42.3 \pm 6.9$ & 0.343 & $44.0 \pm 7.8$ & $42.1 \pm 6.8$ & 0.202 & $41.0 \pm 6.6$ \\
\hline ICU stay time,day & $6.2 \pm 1.4$ & $6.0 \pm 1.4$ & 0.217 & $6.2 \pm 1.2$ & $5.8 \pm 1.5$ & 0.160 & $6.3 \pm 1.9$ \\
\hline $\begin{array}{l}\text { Hospital stay } \\
\text { time,day }\end{array}$ & $21.1 \pm 1.3$ & $19.7 \pm 1.1$ & $<0.001$ & $21.1 \pm 1.3$ & $19.8 \pm 1.1$ & $<0.001$ & $20.9 \pm 1.5$ \\
\hline $\begin{array}{l}\text { Isolated } \\
\text { supracoronary } \\
\text { ascending } \\
\text { aortareplacement,n } \\
(\%)\end{array}$ & 27(39.1) & $134(47.2)$ & 0.228 & $20(40.8)$ & $25(54.3)$ & 0.187 & $7(35.0)$ \\
\hline $\begin{array}{l}\text { Total aortic arch } \\
\text { replacement,n (\%) }\end{array}$ & $24(34.8)$ & $82(28.9)$ & 0.337 & 16(34.8) & $16(32.7)$ & 0.826 & $8(40.0)$ \\
\hline $\begin{array}{l}\text { Partial aortic arch } \\
\text { replacement,n (\%) }\end{array}$ & $14(20.3)$ & $51(18.0)$ & 0.654 & $11(22.4)$ & $4(8.7)$ & 0.066 & $3(15.0)$ \\
\hline others,n (\%) & $4(5.8)$ & $17(6.0)$ & 0.953 & $2(4.1)$ & $1(2.2)$ & 0.595 & $2(10.0)$ \\
\hline \multicolumn{8}{|c|}{ Page $7 / 11$} \\
\hline
\end{tabular}




\begin{tabular}{|c|c|c|c|c|c|c|c|}
\hline Elevated BMI,n (\%) & $36(52.2)$ & $6(2.1)$ & $<0.001$ & $30(61.2)$ & $3(6.5)$ & $<0.001$ & $6(30.0)$ \\
\hline Elevated BP,n (\%) & $67(97.1)$ & 248(87.3) & 0.019 & $48(98.0)$ & $44(95.7)$ & 0.520 & 19(95.0) \\
\hline Elevated FBG,n (\%) & $37(53.6)$ & $63(22.2)$ & $<0.001$ & $35(71.4)$ & $22(47.8)$ & 0.019 & $2(10.0)$ \\
\hline $\begin{array}{l}\text { Reduced HDL-C,n } \\
(\%)\end{array}$ & $37(53.6)$ & $65(22.9)$ & $<0.001$ & $34(69.4)$ & $29(63.0)$ & 0.513 & $3(15.0)$ \\
\hline Elevated TG,n (\%) & $27(39.1)$ & $72(25.4)$ & 0.022 & $23(46.9)$ & $24(52.2)$ & 0.324 & $4(20.0)$ \\
\hline
\end{tabular}

Table 2 Baseline characteristics of the number of METs.

\begin{tabular}{|c|c|c|c|c|c|c|c|c|}
\hline \multirow[t]{3}{*}{ Variables } & \multicolumn{8}{|c|}{ the number of the presence of MetS } \\
\hline & \multirow{2}{*}{$\begin{array}{l}0 \\
n=14\end{array}$} & \multirow{2}{*}{$\begin{array}{l}1 \\
n=137\end{array}$} & \multirow{2}{*}{$\begin{array}{l}2 \\
n=114\end{array}$} & \multirow{2}{*}{$\begin{array}{l}3 \\
n=63\end{array}$} & \multirow{2}{*}{$\begin{array}{l}4 \\
n=21\end{array}$} & \multirow{2}{*}{$\begin{array}{l}5 \\
n=4\end{array}$} & \multirow[t]{2}{*}{$P$ Value } & \multirow[t]{2}{*}{$P \otimes 0.05$} \\
\hline & & & & & & & & \\
\hline Male,n(\%) & 10(71.4) & $111(81.0)$ & $84(73.7)$ & $44(69.8)$ & 13(61.9) & $2(50.0)$ & 0.224 & $\mathrm{e}, \mathrm{i}, \mathrm{l}$ \\
\hline Age,years & $53.4 \pm 4.7$ & $52.1 \pm 4.7$ & $52.3 \pm 5.5$ & $53.4 \pm 4.2$ & $54.1 \pm 7.5$ & $54.0 \pm 3.9$ & 0.340 & \\
\hline $\mathrm{BMI}, \mathrm{Kg} / \mathrm{m} 2$ & $23.5 \pm 2.3$ & $24.6 \pm 2.3$ & $25.2 \pm 2.6$ & $26.8 \pm 3.4$ & $29.8 \pm 3.4$ & $31.1 \pm 0.2$ & $\nabla 0.001$ & $b, c, d, e, g, h, i, j, k, l, m, n$ \\
\hline $\mathrm{HT}, \mathrm{n}(\%)$ & $0(0)$ & $72(52.6)$ & $66(57.9)$ & 49(77.8) & $12(57.1)$ & $3(75.0)$ & $\otimes 0.001$ & $a, b, c, d, e, g, i, j$ \\
\hline T2DM,n(\%) & $0(0)$ & $3(2.2)$ & $28(24.6)$ & 18(28.6) & $11(52.4)$ & $2(50.0)$ & $\otimes 0.001$ & b,c,d,e,f,g,h,i,k,l,m \\
\hline Poor outcome,n(\%) & $0(0)$ & $6(4.4)$ & $14(12.3)$ & $30(47.6)$ & $15(71.4)$ & $4(100.0)$ & $\otimes 0.001$ & b,c,d,e,g,h,i,j,k,l,m,n \\
\hline $\mathrm{SBP}, \mathrm{mmHg}$ & $121.2 \pm 4.9$ & $142.2 \pm 13.2$ & $141.1 \pm 11.2$ & $143.6 \pm 13.4$ & $141.8 \pm 10.5$ & $142.5 \pm 10.3$ & $\nabla 0.001$ & $a, b, c, d, e$ \\
\hline $\mathrm{DBP}, \mathrm{mmHg}$ & $70.2 \pm 7.7$ & $78.9 \pm 6.6$ & $79.8 \pm 6.0$ & $79.5 \pm 7.2$ & $82.9 \pm 5.8$ & $81.0 \pm 6.5$ & $\nabla 0.001$ & $a, b, c, d, e, h, k, m$ \\
\hline HR,bpm & $68.6 \pm 8.4$ & $71.9 \pm 12.1$ & $70.3 \pm 9.8$ & $70.5 \pm 8.4$ & $69.0 \pm 10.7$ & $79.0 \pm 24.8$ & 0.400 & \\
\hline $\mathrm{FBG}, \mathrm{mmol} / \mathrm{L}$ & $5.1 \pm 0.5$ & $5.0 \pm 0.5$ & $5.5 \pm 1.3$ & $6.2 \pm 1.5$ & $6.3 \pm 1.7$ & $7.2 \pm 1.9$ & $\otimes 0.001$ & $c, d, e, f, g, h, i, j, k, l$ \\
\hline $\mathrm{TG}, \mathrm{mmol} / \mathrm{L}$ & $1.1(0.8,1.3)$ & $1.2(0.9,1.5)$ & $1.4(1.1,1.9)$ & $1.8(1.2,2.3)$ & $1.9(1.2,2.8)$ & $1.9(1.8,1.9)$ & $\otimes 0.001$ & $a, b, c, d, e, f, g, h, i, j, k$ \\
\hline WBC,1012/L & $9.7 \pm 1.4$ & $9.9 \pm 1.5$ & $10.0 \pm 1.6$ & $10.3 \pm 1.5$ & $9.8 \pm 1.7$ & $9.3 \pm 1.2$ & 0.635 & \\
\hline PLT,109/L & $214.4 \pm 39.5$ & $224.5 \pm 61.4$ & $225.7 \pm 56.6$ & $206.4 \pm 56.5$ & $209.1 \pm 55.9$ & $209.5 \pm 53.9$ & 0.273 & $f, j$ \\
\hline Length of surgery, min & $274.0 \pm 21.1$ & $276.0 \pm 25.4$ & $275.2 \pm 22.3$ & $276.5 \pm 23.9$ & $275.8 \pm 27.2$ & $272.6 \pm 22.7$ & 0.977 & \\
\hline $\begin{array}{l}\text { Cardiopulmonary bypass time, } \\
\text { min }\end{array}$ & $164.7 \pm 24.8$ & $168.7 \pm 23.8$ & $169.5 \pm 24.5$ & $167.4 \pm 21.2$ & $165.0 \pm 24.1$ & $172.7 \pm 22.9$ & 0.868 & \\
\hline Cross-clamp time, min & $83.6 \pm 16.0$ & $88.8 \pm 12.8$ & $88.9 \pm 12.3$ & $89.3 \pm 16.0$ & $86.5 \pm 12.0$ & $89.3 \pm 10.1$ & 0.775 & \\
\hline Circulatory arrest, min & $41.3 \pm 6.4$ & $41.8 \pm 6.8$ & $43.1 \pm 7.2$ & $42.5 \pm 7.6$ & $44.0 \pm 6.7$ & $42.2 \pm 7.1$ & 0.636 & \\
\hline $\mathrm{HDL}-\mathrm{C}, \mathrm{mmol} / \mathrm{L}$ & $2.3(1.8,3.3)$ & $1.8(1.4,2.3)$ & $1.5(1.0,2.2)$ & $1.0(0.9,1.5)$ & $0.9(0.9,1.1)$ & $0.8(0.5,1.0)$ & $\otimes 0.001$ & $b, c, d, e, f, g, h, i, j, k, l$ \\
\hline LVEF,\% & $55.4 \pm 7.3$ & $57.4 \pm 6.7$ & $57.7 \pm 6.0$ & $56.7 \pm 6.9$ & $56.7 \pm 6.7$ & $54.8 \pm 6.5$ & 0.718 & \\
\hline
\end{tabular}

a:0vs1,b:0vs2,c:0vs3,d:0vs4,e:0vs5,f:1vs2,g:1vs3,h:1vs4,i:1vs5,j:2vs3,k:2vs4,l:2vs5,m:3vs4,n:3vs5,o:4vs5.

Table 3.Impact of MetS components on Poor outcome. 


\begin{tabular}{|c|c|c|c|c|c|}
\hline \multirow[t]{2}{*}{ Variables } & \multicolumn{2}{|c|}{ Quartiles of components } & \multirow[t]{2}{*}{ Poor/Good } & \multirow[t]{2}{*}{$\mathrm{HR}(95 \% \mathrm{Cl})$} & \multirow[t]{2}{*}{$\boldsymbol{P}$ Value } \\
\hline & Range & $\mathbf{n}$ & & & \\
\hline $\mathrm{HT}, \mathrm{n}(\%)$ & - & 202 & $52 / 150$ & $2.092(1.148-3.812)$ & 0.016 \\
\hline T2DM,n(\%) & - & 62 & $15 / 47$ & $1.108(0.590-2.080)$ & 0.749 \\
\hline \multirow[t]{5}{*}{$\mathrm{BMI}, \mathrm{Kg} / \mathrm{m} 2$} & Per quartile & 353 & $69 / 284$ & $1.422(1.205-1.678)$ & $<0.001$ \\
\hline & $\mathrm{Q} 1 \leq 23.45$ & 88 & $1 / 87$ & - & - \\
\hline & $23.45 \rrbracket Q 2 \leq 24.91$ & 87 & $5 / 82$ & $1.003(0.984-1.022)$ & 0.772 \\
\hline & $24.91 \rrbracket Q 3 \leq 27.30$ & 89 & $18 / 71$ & $2.727(1.617-4.597)$ & $<0.001$ \\
\hline & 27.30هQ4 & 89 & $45 / 44$ & $3.306(2.135-5.492)$ & $<0.001$ \\
\hline \multirow[t]{5}{*}{$\mathrm{TG}, \mathrm{mmol} / \mathrm{L}$} & Per quartile & 353 & $69 / 284$ & $1.053(0.841-1.318)$ & 0.654 \\
\hline & Q1 $\leq 1.03$ & 89 & $11 / 78$ & - & - \\
\hline & $1.03 \rrbracket \mathrm{Q} 2 \leq 1.34$ & 88 & $19 / 69$ & $1.581(0.711-3.518)$ & 0.262 \\
\hline & $1.34 \rrbracket \mathrm{Q} 3 \leq 1.78$ & 88 & $17 / 71$ & $1.321(0.583-2.994)$ & 0.504 \\
\hline & $1.78 \rrbracket \mathrm{Q} 4$ & 88 & $22 / 66$ & $1.569(0.735-3.351)$ & 0.244 \\
\hline \multirow[t]{5}{*}{ HDL-C,mmol/L } & Per quartile & 353 & $69 / 284$ & $0.723(0.569-0.918)$ & 0.008 \\
\hline & Q1 $\leq 1.03$ & 88 & $27 / 61$ & - & - \\
\hline & $1.03 \rrbracket Q 2 \leq 1.52$ & 89 & $26 / 63$ & $1.098(0.611-1.973)$ & 0.756 \\
\hline & $1.60 \bigotimes \mathrm{Q} 3 \leq 2.16$ & 91 & $11 / 80$ & $0.710(0.337-1.498)$ & 0.369 \\
\hline & $2.16 \unrhd \mathrm{Q} 4$ & 95 & $5 / 80$ & $0.289(0.107-0.780)$ & 0.014 \\
\hline \multirow[t]{5}{*}{ SBP,mmHg } & Per quartile & 353 & $69 / 284$ & $0.987(0.783-1.244)$ & 0.911 \\
\hline & $\mathrm{Q} 1 \leq 132$ & 89 & $14 / 75$ & - & - \\
\hline & $132 \bowtie Q 2 \leq 140$ & 85 & $14 / 71$ & $0.799(0.359-1.777)$ & 0.582 \\
\hline & $140 \rrbracket Q 3 \leq 149$ & 85 & $23 / 62$ & $1.191(0.576-2.463)$ & 0.637 \\
\hline & 149『Q4 & 94 & $18 / 76$ & $0.939(0.442-1.996)$ & 0.870 \\
\hline \multirow[t]{5}{*}{$\mathrm{DBP}, \mathrm{mmHg}$} & Per quartile & 353 & $69 / 284$ & $1.222(0.980-1.524)$ & 0.075 \\
\hline & $\mathrm{Q} 1 \leq 74$ & 83 & $10 / 73$ & - & \\
\hline & $74 \llbracket Q 2 \leq 80$ & 107 & $18 / 89$ & $1.205(0.518-2.803)$ & 0.665 \\
\hline & $80 \bowtie Q 3 \leq 84$ & 76 & $11 / 65$ & $0.976(0.389-2.451)$ & 0.959 \\
\hline & 84囚Q4 & 87 & $30 / 57$ & $1.537(0.711-3.326)$ & 0.275 \\
\hline \multirow[t]{5}{*}{$\mathrm{FBG}, \mathrm{mmol} / \mathrm{L}$} & Per quartile & 353 & $69 / 284$ & $1.402(1.110-1.771)$ & 0.005 \\
\hline & $\mathrm{Q} 1 \leq 4.7$ & 89 & $13 / 76$ & - & \\
\hline & $4.7 ه Q 2 \leq 5.18$ & 88 & $9 / 79$ & $0.685(0.281-1.668)$ & 0.404 \\
\hline & $5.18 \rrbracket Q 3 \leq 5.7$ & 88 & $10 / 78$ & $0.838(0.355-1.979)$ & 0.687 \\
\hline & 5.7凶Q4 & 88 & $37 / 51$ & $2.239(1.133-4.425)$ & 0.020 \\
\hline
\end{tabular}

Table 4 hazard ratio and $95 \%$ confdence interval for poor outcome of MTEs

\begin{tabular}{|c|c|c|}
\hline \multirow[t]{2}{*}{ Models } & \multicolumn{2}{|l|}{ MetS } \\
\hline & $H R(95 \% \mathrm{Cl})$ & $P$ Value \\
\hline Model 1 & $7.537(4.446-12.775)$ & $₫ 0.001$ \\
\hline Model 2 & $7.369(4.309-12.601)$ & $\varangle 0.001$ \\
\hline Model 3 & $8.036(4.675-8.036)$ & $\nabla 0.001$ \\
\hline Model 4 & $8.137(4.718-14.033)$ & $\varangle 0.001$ \\
\hline Model 5 & $9.905(5.161-19.012)$ & $\varangle 0.001$ \\
\hline
\end{tabular}

Page 9/11 
Model 1:adjusted for Age,male,heart rate囚

Model 2:adjusted for Age,male,heart rate,Aortic valve disease,stroke,LVEF区

Model 3:adjusted for Age,male,heart rate,Aortic valve disease,stroke,LVEF,Length of surgery,Cardiopulmonary bypass time,Cross-clamp time,Circulatory arrest $\$ Model 4:adjusted for Age,male,heart rate,Aortic valve disease,stroke,LVEF,Length of surgery,Cardiopulmonary bypass time,Cross-clamp time,Circulatory arrest,Isolated supracoronary ascending

aortareplacement,Total aortic arch replacement,Total aortic arch replacement,Partial aortic arch replacemen,others,smoker;

Model 5:adjusted for Age,male,heart rate,Aortic valve disease,stroke,LVEF,Length of surgery,Cardiopulmonary bypass time,Cross-clamp time,Circulatory arrest,Isolated supracoronary ascending

aortareplacement,Total aortic arch replacement,Total aortic arch replacement,Partial aortic arch replacemen,others,smoker,WBC,PLT,ICU time, hospital stay time,CR,eGFR,UA

Table 5 Multivariable analysis of the METs components.

\begin{tabular}{lllll} 
Variables & $H R(95 \% \mathrm{Cl})$ & $\boldsymbol{P V}$ Value & Regression Coefficeint & point \\
\hline Elevated BMI & $58.068(20.068-168.153)$ & $<0.001$ & 4.062 & 7 \\
\hline Elevated BP & $5.633(1.009-31.459)$ & 0.049 & 1.729 & 3 \\
\hline Elevated FBG & $4.978(2.370-10.458)$ & $<0.001$ & 1.605 & 3 \\
\hline Reduced HDL-C & $2.917(1.411-6.027)$ & 0.004 & 1.070 & 2 \\
\hline Elevated TG & $1.723(0.810-3.667)$ & 0.158 & 0.544 & 1
\end{tabular}

Table 6 The ROC Curve analysis of the METs with poor outcome

\begin{tabular}{lllllll} 
Factors & AUC & $\boldsymbol{P}$ & $\mathbf{9 5 \%} \mathrm{Cl}$ & $\mathrm{Se}(\%)$ & $\boldsymbol{S p}(\%)$ & Cut off point \\
\hline All Patients & 0.877 & $\square 0.001$ & $0.823-0.932$ & $76.80 \%$ & $90.50 \%$ & 8 \\
\hline MetS & 0.864 & $\square 0.001$ & $0.794-0.935$ & $61.20 \%$ & $93.50 \%$ & 10 \\
\hline non-MetS & 0.700 & $\square 0.001$ & $0.567-0.833$ & $70.00 \%$ & $60.90 \%$ & 4
\end{tabular}

\section{Figures}

Figure 1

Population flowchart of enrolled patients. 


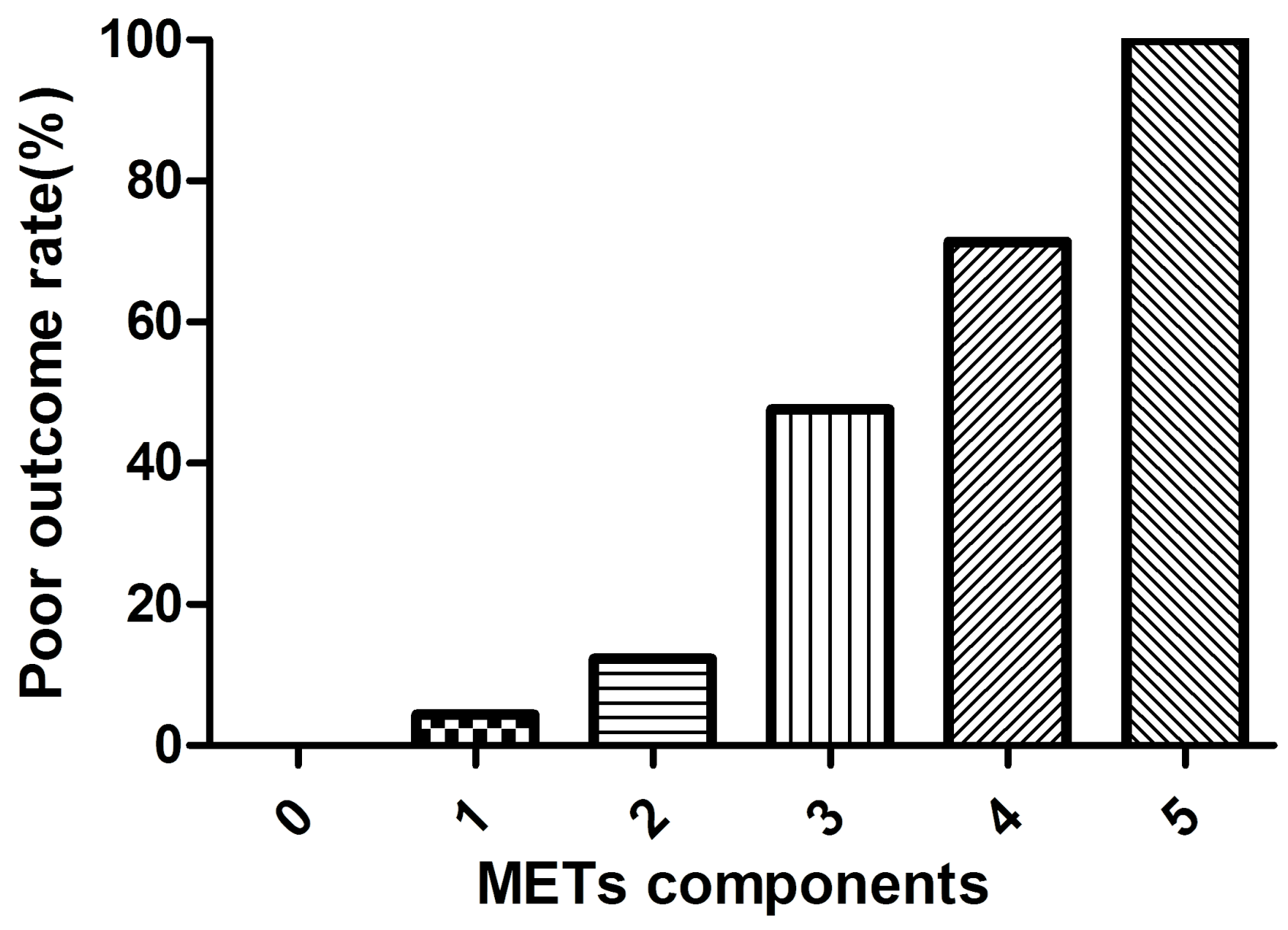

Figure 2

Poor outcome rate of metabolic syndrome components.

Figure 3

ROC curve analysis of the scoring system for the prediction of Poor outcome. 